\title{
Genotype-phenotype correlation in cystic fibrosis patients bearing [H939R;H949L] allele
}

Angela Polizzi ${ }^{1}$, Riccardina Tesse ${ }^{1 *}$, Teresa Santostasi $^{1}$, Anna Diana $^{1}$, Antonio Manca $^{1}$, Vito Paolo Logrillo ${ }^{1}$, Maria Domenica Cazzato ${ }^{2}$, Maria Giuseppa Pantaleo ${ }^{1}$ and Lucio Armenio ${ }^{1}$

${ }^{1}$ Department of Biomedicine of the Developmental Age, Apulian Referral Center for Cystic Fibrosis, Pediatric Unit "S. Maggiore”, University of Bari, Bari, Italy.

${ }^{2}$ Pediatric Unit, "S. Caterina Novella" Hospital, Galatina, Italy.

\begin{abstract}
Cystic fibrosis (CF) is caused by CFTR (cystic fibrosis transmembrane conductance regulator) gene mutations. We ascertained five patients with a novel complex CFTR allele, with two mutations, H939R and H949L, inherited in cis in the same exon of CFTR gene, and one different mutation per patient inherited in trans in a wide population of 289 Caucasian CF subjects from South Italy. The genotype-phenotype relationship in patients bearing this complex allele was investigated. The two associated mutations were related to classical severe CF phenotypes.
\end{abstract}

Key words: CFTR, complex allele, cystic fibrosis, phenotype.

Received: August 3, 2010; Accepted: April 4, 2011.

Cystic fibrosis (CF) is the most common lethal autosomal recessive disorder in the Caucasian population and is caused by mutations in the cystic fibrosis transmembrane conductance regulator (CFTR) gene (Ratjen and Döring, 2003; Lommatzsch and Aris, 2009). This disease has a highly variable clinical presentation with the classical form of CF involving multiple organs, including recurrent respiratory infections, elevated sweat chloride levels, earlyonset pancreatic insufficiency, and infertility in males; CFTR-related disorders (CFTR-RD) are estimated to account for up to $10 \%$ of clinical cases, and symptoms may only affect one organ (Boyle, 2003; Dequeker et al., 2009). The CF phenotype is highly heterogeneous even between siblings carrying identical CFTR mutations, suggesting that the disease severity is affected by the CFTR genotype as well as by environmental and other genetic factors, such as alternative genomic loci containing modifier genes (Rowntree and Harris, 2003). Over 1700 mutations and polymorphisms have been identified throughout the CFTR gene (Cystic Fibrosis Mutation Database), and about onehalf are rare mutations leading to an amino acid substitution into the protein (missense mutations). The number of complex CFTR alleles identified, including double-mutant alleles with two mutations inherited in cis in the same allele has also been growing (Hojo et al., 1998; Abramowicz et

Send correspondence to Polizzi Angela. Laboratorio di Fibrosi Cistica, Dipartimento di Biomedicina dell'Età Evolutiva, Policlinico, Universisety of Bari, Piazza Giulio Cesare 11, 70124 Bari, Italy. E-mail: a.polizzi@pediatria2.uniba.it.

*These authors contributed equally to this work. al., 2000; Clain et al., 2001; Rholfs et al., 2002; Niel et al., 2006; Krasnov et al., 2008, Taulan et al., 2009; Tümmler et al., 2009; de Prada Merino et al., 2010; Lucarelli et al., 2010). They are thought to affect the expression of the phenotype by modulating the effect of mutations: the combination of two missense mutations on the same allele has been described clinically either to improve (Dork et al., 1991; Duarte et al., 1996) or worsen (Hojo et al., 1998) the phenotype of CF patients with regard to the most common mutation alone. In some cases the double-mutant allele has been related with a severe phenotype (Savov et al., 1995; Duarte et al., 1996), while in other cases complex alleles were not associated with classical form of CF (Brugnon et al., 2004). Thus, further data are needed to clarify their functional role. Our Clinic is the referral Center in the Apulia Region of Italy for the diagnosis and follow-up of CF with more than 250 patients examined yearly (only some new diagnoses) in our Institute. In 2005, we have described for the first time in the CF mutation database, the missense mutation H949L, a nucleotide change of A to $\mathrm{T}$ at base pair 2978 in exon 15 of CFTR gene, resulting in a substitution of histidine residue to leucine at codon 949 , as potentially disease-associated allele variation. Lately, McGinniss et al. reported that a 12 year-old male patient carrying the same mutation with a combined dinucleotide TG repeat (of not specified number of repeats) at the intron 8 - exon 9 junction and a thymidine nucleotide tract of 5 nucleotides (5T), had a clinical phenotype suggestive of CFTR-RD, with sinus problem, and an equivocal sweat chloride test result (McGinniss et al., 2005). Notably, it has been demonstrated that the length of 
this poly-T at exon 9 splice site of CFTR gene correlated with the modulation of the exon 9 skipping and with the full length CFTR RNA expression (Chu et al., 1993), and specifically that the splicing variant $5 \mathrm{~T}$ allele associated with partial penetrance of CF disease (Rave-Harel et al., 1997). The Cystic Fibrosis Mutation Database lists the H939R missense mutation, a nucleotide substitution of $A$ to $G$ at base pair 2948 in the same exon of the mutation H949L, corresponding to a histidine to arginine amino acid change at codon 939. The Authors also described the clinical phenothype of the patient, a 17 years old male, with the F508del/H939R genotype, mild expression of a chronic lung disease, pancreatic sufficiency, and unequivocally positive sweat chloride test result.

In this study we evaluated the contribution to the phenotype of the two CF-associated allele mutations [H939R;H949L], combined in cis in the same exon 15 of CFTR gene, which we observed for the first time in 5 unrelated CF patients.

Case histories referring to 289 Caucasian patients [140 male, 149 female, median age 16 years, (range 1-46)], who attended since 1996 our CF Center at the Paediatric Department of the University of Bari, were examined. The diagnosis of $\mathrm{CF}$ was established on the basis of the results of 2 sweat chloride tests $(>60 \mathrm{mEq} / \mathrm{L})$ by Gibson and Cooke procedure, and the identification of two CF-disease causing mutations in trans (Rosenstein and Cutting, 1998; Kulczycki et al., 2003; De Boeck et al., 2006; Castellani et al., 2008; Farrel et al., 2008; Dequeker et al., 2009). The following information was collected: gender, age at diagnosis of CF, CFTR genotype, body mass index (BMI), results of pulmonary function tests [median forced expiratory volume in one second (FEV1), expressed as percentages of predicted values], and exocrine pancreatic status. We adopted the Shwachman-Kulczycki score, one of the most widely used scores, to assess health parameters in our CF patients (Shwachman and Kulczyzki, 1958). The Brasfield scoring system based on plain film radiographic findings was also recorded (Grum and Lynch, 1992). Sputum swabs were obtained from each patient during routine visits (most patients were regularly examinated at 4 month intervals) as well as twice during hospitalization. Chronic airways infection was defined as the presence of Staphilococcus aureus and/or Pseudomonas aeruginosa and/or Burkholderia cepacia in the sputum cultures in three consecutive samples collected in a 6-month period (Brett et al., 1992). Informed consent to collect DNA was obtained from the patients, or, in case of minors, from parents or guardian. Genomic DNA was extracted from peripheral blood leukocytes by standard inorganic methods, using commercial Kit (Genomic DNA Purification Kit -Fermentas Life Sciences, Canada). All CF patients were examined for the most frequent $\mathrm{CF}$ mutations using the RDB (Reverse Dot Blot) commercial kit (InnoLipa CFTR 19, InnoLipa CFTR 17+TnUpdate, InnoLipa CFTR-Italian regional-Innogenetics, Ghent, Belgium). A complete scan of the 27 coding/flanking sequences of the CFTR gene was performed to identify CF alleles carrying unknown mutations, either by denaturing gradient gel electrophoresis (DGGE), using primers and conditions described elsewhere (Fanen et al., 1992; Costes et al., 1993) or by denaturing high performance liquid chromatography (DHPLC) (Le Marechall et al., 2001). Abnormal DGGE and/or DHPLC patterns were followed by automated DNA sequencing using ABI Prism 3100 (Applied Biosystems, Warrington, UK). In most cases, the cis versus trans status of the alterations was obtained by familial segregation assessment, also by using DGGE and automated sequencing tools. Sputum samples from all patients were mixed with equal volumes of $1 \%$ dithiothreitol (Merck, Darmstadt, Germany) before incubation at $37^{\circ} \mathrm{C}$ for $30 \mathrm{~min}$, and cultured isolates were identified by the Phoenix (Becton Dickinson, Sparks, MA, USA) automated system (modified protocol from Efthimiadis et al., 2002).

Detailed information on CFTR genotype, clinical, biological, and functional data from enrolled CF patients, excluding those carrying novel complex alleles, will not be provided because of the different focus of the present report; however this information is available upon request.

During the genetic characterization of the 289 enrolled CF patients a new complex allele [H939R;H949L] (Human Genome Variation Society nomenclature c:[2816A $>$ G;2846A $>$ T] http://www.hgvs.org/ mutnomen) was found in five unrelated patients, in whom the two CF-associated mutations, H939R and H949L, were both carried in the exon 15 on the same allele, as showed in Figure 1. The characteristics of these five patients are summarized in Table 1. The segregation analysis showed that the mother was the carrier of the complex allele [H939R;H949L] in four cases (patients 2, 3, 4 and 5; Table 1), while only in one case (patient 1) the father carried this complex allele (Table 1). We did not find patients bearing the H939R or the H949L mutations alone.

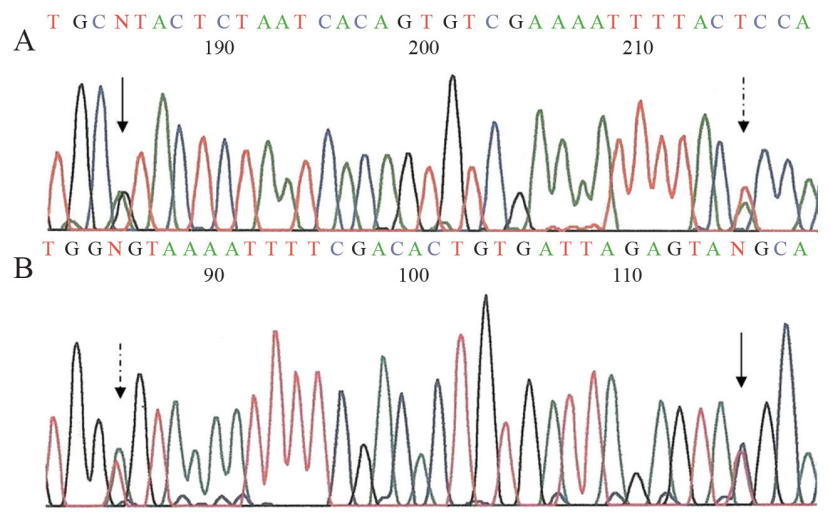

Figure 1 - Sequence electropherograms showing the complex allele [H939R;H949L] in CFTR exon 15, (A) forward and (B) reverse (Forward primer: TCAGTAAGTAACTTTGGCTGC; Reverse primer: CCTATTGATGGTGGATCAGC). Continuous arrows show the H939R mutation while the dashed arrows show the H949L mutation. 
Table 1 - Clinical features of five unrelated patients with the complex allele [H939R;H949L].

\begin{tabular}{|c|c|c|c|c|c|}
\hline Patients characteris* & Patient 1 & Patient 2 & Patient 3 & Patient 4 & Patient 5 \\
\hline Mutation in trans with [H939R;H949L] & $\mathrm{R} 248 \mathrm{~T}$ & G542X & 1259insA & G1349D & F508del \\
\hline Sex & male & male & male & male & male \\
\hline Present age (years) & 15 & 15 & 17 & 20 & 25 \\
\hline Age at diagnosis (years) & 14 & 3 & 0 & 10 & 10 \\
\hline Airways colonization & No & SA & SA & SA & $\mathrm{PA}, \mathrm{BC}$ \\
\hline Age of first colonization (years) & / & 9 & 6 & 12 & 14 \\
\hline $\operatorname{BMI}\left(\mathrm{kg} / \mathrm{m}^{2}\right)$ & 21.9 & 17.0 & 15.1 & 17.6 & 17.5 \\
\hline FEV1 as $\%$ predicted & 84.4 & 114.8 & 80.9 & 93.2 & 53.7 \\
\hline Sweat chloride concentration $(\mathrm{mEq} / \mathrm{L})$ & 78 & 100 & 108 & 92 & 95 \\
\hline S-K score & 100 & 70 & 60 & 75 & 40 \\
\hline Brasfield score ${ }^{\zeta}$ & $\mathrm{N} / \mathrm{A}$ & 5 & 11 & 7 & 21 \\
\hline Pancreas status & PS & PI & PI & PI & PI \\
\hline Diagnosis & CFTR-RD & $\mathrm{CF}$ & $\mathrm{CF}$ & $\mathrm{CF}$ & $\mathrm{CF}$ \\
\hline
\end{tabular}

$\mathrm{SA}=$ Staphilococcus aureus, $\mathrm{PA}=$ Pseudomonas aeruginosa, $\mathrm{BC}=$ Burkholderia cepacia; $\mathrm{N} / \mathrm{A}=$ not applicable; $\mathrm{S}-\mathrm{K}=$ Shwachman-Kulczycki: the system is based on four parameters (general activity, physical examination, growth and nutrition and chest radiograph x-ray), and is rated as a) excellent: 86-100 b) good: 71-85, c) mild: 56-70, d) moderate: 41-55, and e) severe: < 40 (Shwachman and Kulczyzki, 1958); 'scoring system from 3 "mild" to 25 "most severe" (Brett et al., 1992) after x-ray; PS/PI = Pancreatic sufficiency/insufficiency. CF = cystic fibrosis; CFTR-RD = CF transmembrane conductance regulator-related disorder.

*Patients' enrolment was done based on symptoms.

Patient 1 showed CF-related symptoms and signs restricted to one organ. In fact he presented only hepatopathy with high levels of transaminases combined with elevated sweat chloride concentration. His Shwachman-Kulczycki score was excellent; he showed a good nutritional status and pancreatic sufficiency. The diagnosis of this disease was made relatively late. The other four patients had signs and symptoms consistent with classic $\mathrm{CF}$, including chronic lung and sinus disease, recurrent respiratory infections, failure to thrive and pancreatic insufficiency. They all showed abnormal sweat chloride values. Particularly, patient 3 presented with meconium ileus as a neonate, and patient 5 showed the most severe pulmonary manifestation of $\mathrm{CF}$ with generalized hyperinflation and diffuse nodular, cystic and coarse reticular opacities in the lung, with abnormal values on tests of lung function (Table 1).

During our screening analysis we also found thirteen males affected by congenital bilateral absence of vas deferens (CBAVD) bearing the intron 8 (IVS-8) variants TG13-T5 and TG12-T5 in compound heterozygosity with associated CF-causing mutations, and 2 sisters (of 7 and 9 years old respectively) carrying the [R668C;G576A] complex allele in compound heterozygosity with F508del CF mutation, showing a borderline sweat chloride test, recurrent asthmatic bronchitis and pancreatic sufficiency.

Complex disease alleles are rare (we have found only few cases screening a wide population of CF patients from South Italy) and very interesting (the second mutation in cis can modulate the effect of the first or viceversa). To our knowledge the complex allele [H939R;H949L] and its correlation to the $\mathrm{CF}$ phenotype were not previously described.
In the afore mentioned database the R248T mutation that we found in patient 1 was described as "mild", occurring in male patients with CBAVD and no other signs or symptoms, even when associated with another severe mutation. The other four patients were compound heterozygotes respectively for G542X, 1259insA, G1349D, F508del and the two associated mutation in exon 15 [H939R;H949L]. The mutations G542X, 1259insA, G1349D, F508del have already been described as severe CF-asssociated mutation (Casals et al., 1993; Morral et al., 1993; Morral et al., 1994; Kerem et al., 1995; Estivill et al., 1997; Shrimpton et al., 1997; Rowntree and Harris 2003; Bompadre et al., 2007; Castellani et al., 2008). Particularly, 1259insA and G1349D represent with few other mutations, 4382delA, I502T, 852del22, 4016insT, D579G, R1158X and L1077P, almost $20 \%$ of the CF alleles found in the Apulian population (Castaldo et al., 2005; Polizzi et al., 2005). The 1259insA results in the increase of a string of four As into five, which leads to the premature termination of product due to the formation of a stop codon, as described by Shrimpton et al. (defective protein production, class I mutation) (Shrimpton et al., 1997). Also the G542X prevents the synthesis of full-length, normal CFTR protein due to the creation of a premature termination codon (Rich et al., 1993; Rowntree and Harris, 2003). On the other hand, the F508del mutation, a deletion of three bases encoding a phenylalanine residue at position 508 within the first nucleotide binding domain (NBD), affects CFTR maturation (class II mutations) (Rowntree and Harris, 2003), while the G1349D plays a role in ATP-dependent opening of the chloride channel, resulting in a defective CFTR activation 
and regulation (class III) (Bompadre et al., 2007). We speculate that both mutations H939R and H949L might affect the second NBD of CFTR and have a role in altering the conductance of the chloride channel, but to our knowledge there are no reports on their functions.

In our study, the four patients carrying the complex allele [H939R;H949L] associated in trans with the severe mutations G542X, 1259insA, G1349D and F508del presented the classic CF phenotype. On the contrary, patient 1 who carried the same complex allele with the R248T mutation showed a CFTR-RD (Table 1). This is likely due to the fact that R248T is a mild mutation (thought to affect CFTR mRNA splicing based on the database: Cystic Fibrosis Mutation Database), and subjects carrying this mutation might have a residual function of the CFTR protein. It seems that the complex allele [H939R;H949L] greatly reduces the residual function of CFTR and, when also on the other allele is present a severe mutation which produces a very low residual function, the combined effect is an overall great reduction of CFTR functionality; on the contrary, when the other allele carries a mild mutation, the overall effect is a cumulative greater CFTR functionality.

We also found in our $\mathrm{CF}$ population subjects carrying the variant tracts TG13-T5 and TG12-T5, which have been already described in males with CBAVD in the literature (Castellani et al., 2008; Dequeker et al., 2009), and the [R668C;G576A] complex allele. The R668C in exon 13 is considered a polymorphism (Pignatti et al., 1994) while the G576A, in CFTR exon 12, seems to induce a variable extent of exon skipping that leads to reduced levels of normal CFTR transcripts (Pagani et al., 2003).

The complex alleles and their role in disease pathogenesis still remain a challenge for both researchers and clinicians, thus more information on our newly discovered complex allele [H939R;H949L] or on the H939R and the H949L mutations alone would help to study the effect on the phenotype of these rare mutations.

\section{References}

Abramowicz MJ, Dessars B, Sevens C, Goossens M and Girodon-Boulandet E (2000) Fetal bowel hyperechogenicity may indicate mild atypical cystic fibrosis: A case associated with a complex CFTR allele. J Med Genet 37:E15.

Bompadre SG, Sohma Y, Li M and Hwang TC (2007) G551D and G1349D, two CF-associated mutations in the signature sequences of CFTR, exhibit distinct gating defects. J Gen Physiol 129:285-298.

Boyle MP (2003) Non classic cystic fibrosis and CFTR-related diseases. Curr Opin Pulm Med 9:498-503.

Brett MM, Simmonds EJ, Ghonheim ATM and Littlewood JM (1992) The value of serum IgG titres against Pseudomonas aeruginosa in the management of early infection in cystic fibrosis. Arch Dis Child 67:1086-1088.

Brugnon F, Bilan F, Heraud MC, Grizard C, Janny L and Creveaux I (2004) Outcome of intracytoplasmic sperm injection for a couple in which the man is carrier of
[R74W;V201M;D1270N] and P841N mutations and his spouse a heterozygous carrier of F508del mutation of CFTR gene. Fertil Steril 90:23-26.

Casals T, Nunes V, Palacio A, Giménez J, Gaona A, Ibáñez N, Morral N and Estivill X (1993) Cystic fibrosis in Spain: High frequency of mutation G542X in the Mediterranean coastal area. Hum Genet 91:66-70.

Castaldo G, Polizzi A, Tomaiuolo R, Cazeneuve C, Girodon E, Santostasi T, Salvatore D, Raia V, Rigillo N, Goossens M, et al. (2005) Comprehensive cystic fibrosis mutation epidemiology and haplotype characterization in a southern Italian population. Ann Hum Genet 69:15-24.

Castellani C, Cuppens H, Macek M Jr, Cassiman JJ, Kerem E, Durie P, Tullis E, Assael BM, Bombieri C, Brown A, et al. (2008) Consensus on the use and interpretation of cystic fibrosis mutation analysis in clinical practice. J Cyst Fibros 7:179-196.

Chu CS, Trapnell BC, Curristin S, Cutting GR and Crystal RG (1993) Genetic basis of variable exon 9 skipping in cystic fibrosis transmembrane conductance regulator mRNA. Nat Genet 3:151-156.

Clain J, Fritsch J, Lehmann-Che J, Bali M, Arous N, Goossens M, Edelman A and Fanen P (2001) Two mild cystic fibrosis-associated mutations result in severe cystic fibrosis when combined in cis and reveal a residue important for cystic fibrosis transmembrane conductance regulator processing and function. J Biol Chem 276:9045-9049.

Costes B, Fanen P, Goossens M and Ghanem N (1993). A rapid, efficient, and sensitive assay for simultaneous detection of multiple cystic fibrosis mutations. Hum Mutat 2:185-191.

De Boeck K, Wilschanski M, Castellani C, Taylor C, Cuppens H, Dodge J, Sinaasappel M and Diagnostic Working Group (2006) Cystic fibrosis: Terminology and diagnostic algorithms. Thorax 61:627-635.

Dequeker E, Sthrmann M, Morris MA, Casals T, Castellani C, Claustres M, Cuppens H, des George M, Fere C, Macek M, et al. (2009) Best practice guidelines for molecular genetic diagnosis of cystic fibrosis and CFTR-related dosordersupdate European recommendations. Eur J Hum Genet 17:51-65.

de Prada Merino A, Bütschi FN, Bouchardy I, Beckamann JS, Morris MA, Hafen GM and Fellmann F (2010) [R74W;R1070N;D1270N]: A new complex allele responsible for cystic fibrosis. J Cist Fibros 9:447-449.

Dork T, Wulbrand U, Richter T, Neumann T, Wolfes H, Wulf B, Maass G and Tummler B (1991) Cystic fibrosis with three mutations in the cystic fibrosis transmembrane conductance regulator gene. Hum Mutat 87:441-446.

Duarte A, Amaral M, Barreto C, Pacheco P and Lavinha J (1996) Complex cystic fibrosis allele R334W-R1158X results in reduced levels of correctly processed mRNA in a pancreatic sufficient patient. Hum Mutat 8:134-139.

Efthimiadis A, Spanevello A, Hamid Q, Kelly MM, Linden M, Louis R, Pizzichini MM, Pizzichini E, Ronchi C, Van Overvel F, et al. (2002) Methods of sputum processing for cell counts, immunocytochemistry and in situ hybridisation. Eur Respir J Suppl 37:19s-23s.

Estivill X, Bancells C and Ramos C (1997) Geographic distribution and regional origin of 272 cystic fibrosis mutations in European populations. The Biomed CF Mutation Analysis Consortium. Hum Mutat 10:135-154. 
Fanen P, Ghanem N, Vidaud M, Besmond C, Martin J, Costes B, Plassa F and Goossens M (1992) Molecular characterization of cystic fibrosis: 16 novel mutations identified by analysis of the whole cystic fibrosis conductance transmembrane regulator (CFTR) coding regions and splice site junctions. Genomics 13:770-776.

Farrell PM, Rosenstein BJ, White TB, Accurso FJ, Castellani C, Cutting JR, Durie MP, LeGryse VA, Massie J, Parad RB, et al. (2008) Guidelines for diagnosis of cystic fibrosis in new borns through older adults: Cystic Fibrosis Foundation Consensus Report. J Pediatr 153:S4-S14.

Hojo S, Fujita J, Miyawaki H, Obayashi Y, Takahara J and Bartholomew DW (1998) Severe cystic fibrosis associated with a $\Delta \mathrm{F} 508 / \mathrm{R} 347 \mathrm{H}+\mathrm{D} 979 \mathrm{~A}$ compound heterozygous genotype. Clin Genet 53:50-53.

Grum CM and Lynch 3rd JP (1992) Chest radiographic findings in cystic fibrosis. Semin Respir Infect 7:193-209.

Kerem E and Kerem B (1995) The ralationship between genotype and phenotype in cystic fibrosis. Curr Opin Pulm Med 1:450-456.

Krasnov KV, Tzetis M, Cheng J, Guggino WB and Cutting GR (2008) Localizzation studies of rare missense mutations in cystic fibrosis transmembrane conductance regulator (CFTR) facilitate interpretation of genotype-phenotype relationships. Hum Mutat 29:1364-1372.

Kulczycki LL, Kostuch M and Bellanti JA (2003) A clinical prospective of cystic fibrosis and new genetic findings: Relationship of CFTR mutations to genotype-phenotype manifestations. Am J Med Genet 116:262-267.

Le Marechal C, Audrezet MP, Quere I, Raguenes O, Iangonne O and Ferec C (2001) Complete and rapid scanning of the cystic fibrosis transmembrane conductance regulator (CFTR) gene by denaturing high-performance liquid chromatography (DHPLC): Major inplications for genetics counseling. Hum Genet 108:290-298

Lommatzsch ST and Aris R (2009) Genetics of cystic fibrosis. Semin Respir Crit Care Med 30:531-538.

Lucarelli M, Narzi L, Pierandrei S, Bruno SM, Stamato A, d'Avanzo M, Strom R and Quattrucci S (2010) A new complex allele of the CFTR gene partially explains the variable phenotype of the L997F mutation. Genet Med 12:548-555.

McGinniss MJ, Chen C, Redman JB, Buller A, Quan F, Peng M, Giusti R, Hantash FM, Huang D, Sun W, et al. (2005) Extensive sequencing of the CFTR gene: Lessons learned from the first 157 patient samples. Hum Genet 118:331-338.

Morral N, Bertranpetit J, Estivill X, Nunes V, Casals T, Giménez J, Reis A, Varon-Mateeva R, Macek Jr M, Kalaydjieva L, et al. (1994) The origin of the major cystic fibrosis mutation (delta F508) in European populations. Nat Genet 7:169-175.

Morral N, Nunes V, Casals T, Chillón M, Giménez J, Bertranpetit J and Estivill X (1993) Microsatellite haplotypes for cystic fibrosis: Mutation frameworks and evolutionary tracers. Hum Mol Genet 2:1015-1022.

Niel F, Legendre M, Bienvenu T, Bieth E, Lalau G, Sermet I, Bondeux I, Boukari R, Derelle J, Levy P, et al. (2006) A new large CFTR rearrangement illustrates the importance of searching for complex alleles. Hum Mutat 27:716-717.
Pagani F, Stuani C, Tzetis M, Kanavakis E, Efthymiadou A, Doudounakis S, Casals T and Baralle FE (2003) New type of disese causing mutations: The example of composite exonic regulatory elements of splicing in CFTR exon 12. Hum Mol Genet 12:1111-1120.

Pignatti F, Bombieri C, Marigo C, Benetazzo M and Luisetti M (1995) Increased incide of cystic fibrosis gene mutations in adults with disseminated bronchiectasis. Hum Mol Genet 4:635-639.

Polizzi A, Francavilla R, Castaldo G, Santostasi T, Tomaiuolo R, Manca A, De Robertis F, Mappa L, Oliverio FP, Salvatore F, et al. (2005) Phenotypic expression of genotype-phenotype correlation in cystic fibrosis patients carrying the 852 del 22 mutation. Am J Med Genet 132:434-440.

Ratjen F and Döring G (2003) Cystic fibrosis. Lancet 361:681-689.

Rave-Harel N, Kerem E, Nissim-Rafinia M, Madjar I, Goshen R, Augarten A, Rahat A, Hurwitz A, Darvasi A and Kerem B (1997) The molecular basis of partial penetrance of splicing mutations in cystic fibrosis. Am J Hum Genet 60:87-94.

Rich DP, Gregory RJ, Cheng SH, Smith AE and Welsh MJ (1993) Effect of deletion mutations on the function of CFTR chloride channels. Receptors Channels 1:221-232.

Rohlfs EM, Zhou Z, Surgaman EA, Heim RA, Pace RG, Knowles MR, Silverman LM and Allitto BA (2002) The I148T CFTR allele occurs on multiple haplotypes: A complex allele is associated with cystic fibrosis. Genet Med 4:319-323.

Rosenstein B and Cutting G (1998) The diagnosis of cysti fibrosis: A consensus statement. Cystic Fibrosis Foundation Consensus Panel. J Pediatr 132:589-595.

Rowntree RK and Harris A (2003) The phenotypic consequences of CFTR mutations. Ann Hum Genet 67:471-485.

Savov A, Angelicheva D, Balassopoulou A, Jordanova A, Noussia-arvanitakis S and Kalaydjieva L (1995) Double mutant alleles: Are they rare? Hum Mol Genet 4:1169-1171.

Shrimpton AE, Borowitz D and Swender P (1997) Cystic fibrosis mutation frequency in Upstate New York. Hum Mutat 10:436-442.

Shwachman H and Kulczyzki LL (1958) Long term study of 105 patients with cystic fibrosis. Am J Dis Child 96:6-15.

Taulan M, Guittard C, Theze C, Claustres M and Georges M (2009) A novel double deletion underscores the importance of characterizing end points of the CFTR large rearrangements. Eur J Hum Genet 17:1683-1687.

Tümmler B, Stanke F, Bronsveld I, Veeze H and Ballmann M (2009) Transient correction of the basis in sweat glands in an individual with cystic fibrosis carrying the complex CFTR allele F508del-R553Q. Thorax 64:179-80.

\section{Internet Resources}

Cystid Fibrosis Mutation Database: http://www.genet.sickkids. on.ca/cftr (July 7, 2010).

Associate Editor: Angela M. Vianna-Morgante

License information: This is an open-access article distributed under the terms of the Creative Commons Attribution License, which permits unrestricted use, distribution, and reproduction in any medium, provided the original work is properly cited. 